\title{
Investigating crashworthy single and double skin structures against accidental ship-to-ship interaction
}

https://doi.org/10.1515/cls-2018-0013

Received Mar 20, 2018; accepted Apr 17, 2018

\begin{abstract}
During ship collision, hull crashworthiness is an important data which needs to be assessed as rapid development of hull structure has taken into consideration since several notable dangerous events. After catastrophic accidents cause both tragic loss of life and destruction of maritime environment, double skin system is applied for almost all ships, including RoRo passengers. This work aimed to assess effects of selected internal parameters to crashworthiness criteria, considering a passenger vessel as the target of a series of impact loads. A set of collision scenario was numerically designed using finite element (FE) method by involving single and double skin structures, target location and material grade to obtained estimation of hull crashworthiness. Assessment was focussed on the energy absorption, crushing force, stress level and failure strain of the target ship after experiencing side collisions. It was obtained from the analyses regarding role of the inner skin on tendency of the energy absorption. Failure progress on the proposed structures was successfully quantified based on stress expansion. Minimum value of material strength was concluded in final discussion to reduce more massive failure.
\end{abstract}

Keywords: Ship collision; finite element method; single and double skin structures; material grades; crashworthiness criteria

\footnotetext{
*Corresponding Author: Jung Min Sohn: Interdisciplinary Prog. Marine Convergence Design, Pukyong National University, Busan, South Korea; Dept. Naval Architecture and Marine Systems Engineering, Pukyong National University, Busan, South Korea; Email: jminz@pknu.ac.kr; Tel. +82 (0) 516296618; Fax. +82 (0) 516296608 Aditya Rio Prabowo: Interdisciplinary Prog. Marine Convergence Design, Pukyong National University, Busan, South Korea; Dept. Naval Architecture, Universitas Diponegoro, Semarang, Indonesia Dong Myung Bae: Dept. Naval Architecture and Marine Systems Engineering, Pukyong National University, Busan, South Korea Ahmad Fauzan Zakki, Bangun IR Harsritanto: Dept. Naval Architecture, Universitas Diponegoro, Semarang, Indonesia
}

\section{Introduction}

The safety of ships is the main concern of many parties especially designer, engineer and passenger. Demand to improve the structural design has been responded with rapid development, especially in hull structure region. According to evaluation on safety and shipping 1912-2012, merchant ships have been given special attention after several accidental disasters occur on it, such as collision, grounding and foundering [1]. Numbers of effort to avoid stability loss and slow oil spillage were already performed since two years after Oil Pollution Act (OPA). The International Convention for the Prevention of Pollution (the MARPOL convention) was significantly amended to require all new built tankers have double hull systems [2]. Advance improvement in naval technology and high request for more safety on other ship types, make the double hull system is also implemented in modern bulk carrier, container ship and RoRo passenger. It was widely realised that the complexity of accidental collision occurred due to various parameters were involved in this phenomenon, such as loading condition and structural solution (e.g. double hull and framing system). The mentioned parameter can be translated as the critical factors of the steel structure on ship, which highly influence structural behaviour and failure after any maritime accident. Variety of ship type and size these days requires further investigation to expand analysis and damage estimation to other than ship included in common structural rules (for example conducted in [37]). Besides this condition, safety priority is also realised important for passenger ship which pushes continuous assessment damage estimation as reference data in improving mitigation scheme.

This paper was conducted as sustainable research of pioneer works in collision incident to double hull structures [8] which consider width between two side hulls. In other work, striking speed was varied to assess both damage and progressive failure on the target ship [9]. Current work will expand the previously-applied parameters to 
structural behaviours of a passenger ship under accidental side collision with other ship. Focus was addressed to assess several crashworthiness criteria to evaluate structural resistance. Energy absorption and failure extent would be summarized based on selected target location on the ship. Effect of internal parameter such as material type was simultaneously discussed to observe crashworthy passenger ship affected by determined material standard by international association.

\section{Literature review}

\subsection{Pioneer works and development in analysis}

Structural resistance to impact phenomenon has become one of among safety parameters for ship and marine structures. Resistance is mainly assessed when a structure against impact loads, such as explosion, grounding and collision. Numbers of efforts from previous researchers to investigate structural performance subjected to accidental impact are reported in their works. Investigation to several ships carrying dangerous cargo, such as nuclear fuel was initiated by Minorsky who later famous with his empirical expression to predict amount of absorbed energy based on damaged structure volume [10]. After approximately five decades, assumption of worse case by Minorsky for global motion of ship collision was considered in analytical analysis to design simplified ship collision model [11]. The analytical equation for ship motion was also presented by Lützen during investigated the relation between probability a series of collision scenario and ship collision damage [12]. Actual experiment project to produce prediction methodology of tanker failure and resulting oil spill was carried in Japan from 1991 to 1997. Almost in same time, actual full-scale ship collision experiment was carried jointly by Japan and the Netherlands using $80 \mathrm{~m}$ tankers. Following this experiment, new projects of ship-ship collisions were carried by Japan-the Netherlands-Germany in November 1997. Two structure designs of Very Large Crude Carrier (VLCC) were used as the struck ship [13]. As advance development of computational technology, collision analysis can be possibly conducted by virtual experiment. Modelling technique to simulate structural crashworthiness in ship collision was fundamentally described, and later validation for the theory was given by Paik [14, 15]. In early of the twentieth century, Kitamura also stated conditions to produce reliable collision scenario using virtual analysis [16]. Both studies provided good agreement in terms of finite element method (FEM) application for accidental events. This analysis fashion continued to be used for impact analysis, such as recent works by Haris and Amdahl [17], Liu and Soares [18] and Prabowo et al. [19]. In aspects of experiment and simulation, the finite element (FE) approach is judged well enough to produce reliable results and can be used to perform other varieties of collision scenario with reasonable time and cost. Assessment of structural behaviour on maritime passenger transportation is considered as good research opportunity since previous works on accidental collision and grounding was already focussed on nuclear powered ship, bulk carrier and oil tanker. Furthermore, even though navigation method has been developed by pioneer study, such as by Szłapczyński and Śmierzchalski [20], the accidental collision still possibly occur with limitless possibilities and causes.

\subsection{Fundamental on energy absorption and steel requirement}

According empirical formulae from several known researchers namely Minorsky [10], Zhang [13], Woisin [21], $\mathrm{Lu}$ and Callidine [22], and Paik [23] the absorbed energy during collision is proportionally equal with volume of the destroyed material. Mathematical formulae to estimate the absorbed energy by empirical method are presented in Equations 1 to 5 . The absorbed energy can be accessed on the internal energy output during assessment by nonlinear FE methodology. Cross-check of these methods have been performed (see works [24, 25]), which correlation of two methods was successfully achieved, especially with the developed forms by Zhang [11]. Minorsky formula was concluded match with high-collision energy, especially on collision analysis involving VLCC or Suezmax carrier.

$$
\begin{array}{rr}
E_{a b s}=47.2 R_{t}+32.7 & {[10]} \\
E_{a b s}=0.77 \cdot \varepsilon_{c} \cdot \sigma_{0} \cdot R_{t} & {[13]} \\
E_{a b s}=47.2 R_{T}+0.5 \sum\left(h \cdot t_{s}{ }^{2}\right) & {[21]} \\
E_{a b s}=C . \sigma_{0} \cdot l^{1.4} \cdot t^{1.6} & {[22]} \\
E_{a b s}=C_{1.5} \cdot \sigma_{0} \cdot l^{1.5} \cdot t_{e q}{ }^{1.5} & {[23]}
\end{array}
$$

where $E_{a b s}$ is the absorbed energy; $R_{T}$ is the destroyed material volume for both struck and striking ship / resistance factor; $C$ has value in the range $0.9-3.5$; $\sigma_{0}$ is the flow stress of material; $l$ is the length of cut; $t$ is the thickness of the plate; $C_{1.5}$ equals with $1.112-1.156 \theta+3.760 \theta^{2}$ where $\theta$ is the half of the wedge; $t_{e q}$ is the equivalent plate thickness; and $\epsilon_{c}$ is the critical rupture strain of the material which is determined from $\epsilon_{c}=0.10\left(\epsilon_{f} / 0.32\right)$ where $\epsilon_{f}$ is the steel material ductility obtained in tensile test. 
Table 1: IACS requirements for material specification [26].

\begin{tabular}{lcccccccc}
\hline $\begin{array}{l}\text { Steel } \\
\text { grade }\end{array}$ & \multicolumn{2}{c}{ Composition of main compounds } \\
\cline { 2 - 9 } & $\mathrm{C} \%$ & $\mathrm{Mn} \%$ & $\mathrm{Si} \%$ & $\mathrm{P} \%$ & $\mathrm{~S} \%$ & Al \% & $\begin{array}{c}\text { Yield strength } \\
\text { (MPa) }\end{array}$ & $\begin{array}{c}\text { Ultimate } \\
\text { strength (MPa) }\end{array}$ \\
\hline $\mathrm{A}$ & 0.21 & $2.5{ }^{*} \mathrm{C}$ & 0.5 & 0.035 & 0.035 & - & 235 & $400-520$ \\
$\mathrm{~B}$ & 0.21 & 0.8 & 0.35 & 0.035 & 0.035 & - & 235 & $400-520$ \\
$\mathrm{D}$ & 0.21 & 0.6 & 0.35 & 0.035 & 0.035 & 0.015 & 235 & $400-520$ \\
$\mathrm{E}$ & 0.18 & 0.7 & 0.35 & 0.035 & 0.035 & 0.015 & 235 & $400-520$ \\
\hline
\end{tabular}

Characteristic of the absorbed energy after the striking ship contacts with the struck ship can be considered as the reaction of the structural resistance. Fundamentally, a typical ship structure consists three main elements, i.e. steel material, framing style and hull arrangement. Especially for the steel material, International Association of Classification Society (IACS) classify the steel in four grade levels, such as Grade A, Grade B, Grade D and Grade E [26]. These grades are labelled as the material requirement for ship hull, and each grade has different specification in terms of composition and strength (Table 1). Material itself supports the other structural criteria, and holds important role in providing hull resistance against penetration.

\section{Collision analysis}

\subsection{Ship geometry and configuration}

There were two ships used in this study, which denoted as the struck and striking ships. The struck ship was determined as the target during side collision took place. In other hand, side penetration on side hull of the struck ship would be conducted by the striking ship which acted as an indenter. Illustrations of the involved ships and collision are shown in Figure 1. The struck ship was modelled after an $85 \mathrm{~m}$ passenger ship while the striking ship was an idealisation of a $144 \mathrm{~m}$ cargo carrier with dimension of both ships is presented in Table 2.

The ship geometry were built in concept of thin-walled hull with the structural model was arranged based on the shell element. Ordinary Belytschko-Tsay (element formulation number - EF no. =1) embedded in ANSYS LS-DYNA explicit codes [27] was implemented on both ships. Effectiveness of this formulation for nonlinear assessment, such as grounding and collision, has been discussed in pioneer study. It was found that Belytschko-Tsay was superior to other proposed elements, e.g. Belytschko-Leviathan and Belytschko-Wong-Chiang [28].
Meshing size was considered important, especially for the struck ship which defined as the deformable structures. Too small sizes would lead to unreasonable time process, and large sizes would give unnatural deformation pattern. Therefore, three mesh sizes were applied based on the ratio between the element lengths and element thickness, which widely used in automobile industry [29]. The applied size was given according to the role of structural parts during ship collision. There were three zones designated on the struck ship, namely core, transition and outer zones. The core zone was defined as the zone where contact between two bodies would take place and the smallest mesh with ratio 8 was applied on it. Besides this location, the transition zone were given larger size mesh than the first zone, specifically with ratio value 9 . Terminology transition was given as its location between the core and outer zones. The final part was the outer zone. Since no deformation was expected in this part, meshing size with larger size than two other zones, was given here to reduce calculation time. The steel material followed configuration of the plastic-kinematic models with input values were given as follows: density $\rho=7870 \mathrm{~kg} / \mathrm{m}^{3}$; modulus elasticity $E_{X}=200000 \mathrm{MPa}$; yield strength $\sigma_{Y}=370 \mathrm{MPa}$; Poisson's ratio $v=0.29$; hardening number $n=0$; Cowper-Symonds parameters $C=32001 / \mathrm{s}$ and $P=5$; and failure strain $\epsilon_{f}=$ 0.2 .

Material strength would be varied to provide comparative structural strength on the struck ship. Detail of the proposed material properties would be denoted as materials I-IV for IACS grades A-D respectively. These material arrangements were shown in Table 3. During interaction of two ships took place, it was expected that the rigid-striking ship would penetrate side hull of the struck ship. In this situation, immense structural damage was expected which definition failure in this work was given as condition of the material exceeded their ultimate strain limit due to the side impact. However, it was well realised that it was complicated task to trace the strain history of material element at very detailed level, especially in complex structures, such as ship. Therefore, the maximum strain failure criterion 
Table 2: Main dimension of the involved ships in collision analysis.

\begin{tabular}{lcc}
\hline Dimension & Struck ship - passenger ship & Striking ship - cargo carrier \\
\hline Length over all $(\mathrm{m})$ & 85.92 & 144.50 \\
Breadth moulded $(\mathrm{m})$ & 15.00 & 19.80 \\
Design draft $(\mathrm{m})$ & 4.30 & 5.60 \\
Depth $(\mathrm{m})$ & 10.40 & 10.20 \\
Frame spacing $(\mathrm{mm})$ & 600 & - \\
Double shell width $(\mathrm{m})$ & 1.50 & - \\
\hline
\end{tabular}
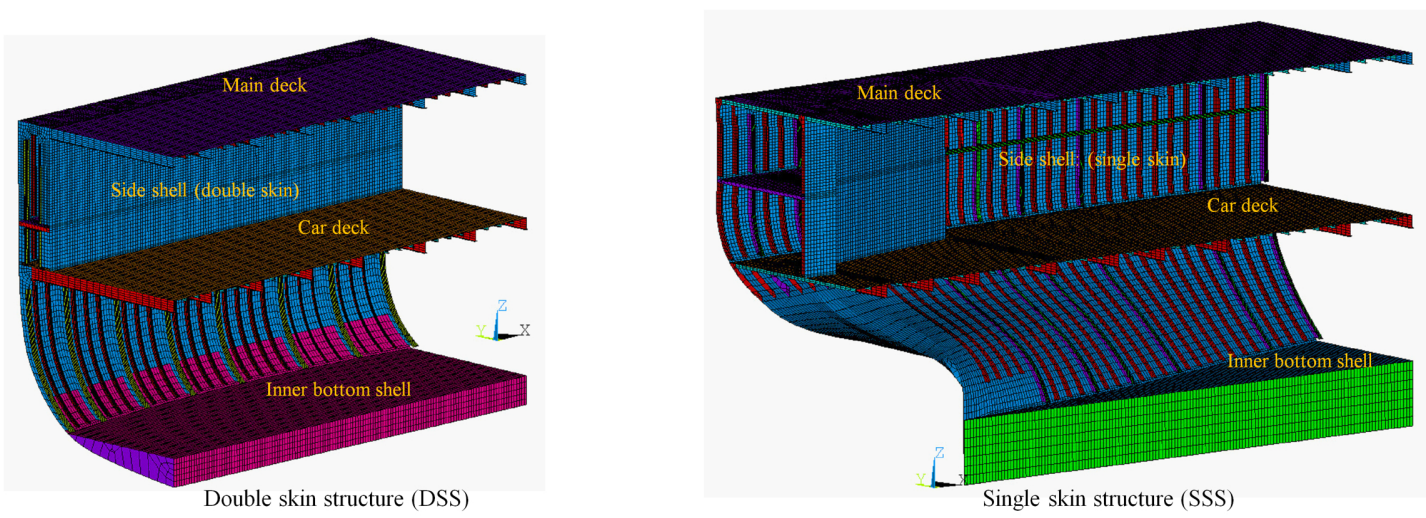

(a)

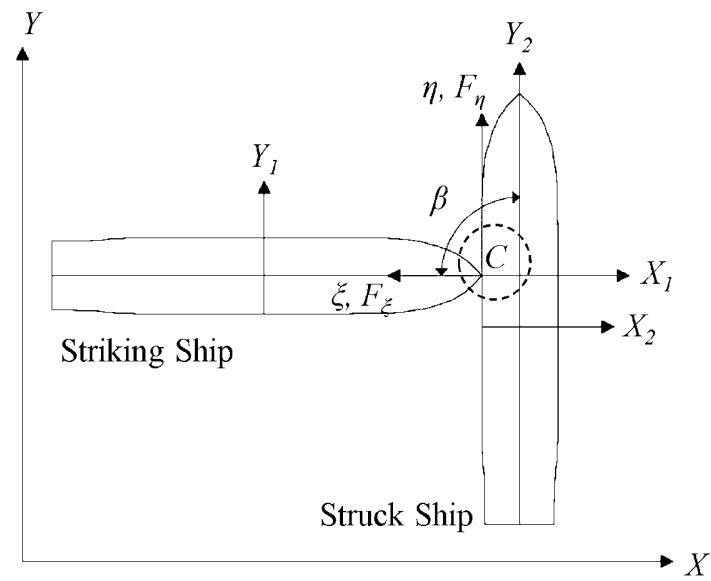

- Considering a striking ship, which sails at a forward speed of $V_{X I}$ and a sway speed of $V_{Y 1}$. This vessel collides with a struck ship, sailing at a forward speed of $V_{Y 2}$ and a speed of $V_{X 2}$ in the sway direction, is considered

- The theory makes use of three different coordinate systems. A Cartesian coordinate system is fixed to the sea bottom

- The $Z$-axis points in a direction out of the water surface, the $X$-axis lies in the symmetry plane of the struck ship pointing towards the bow, and the origin of the Cartesian coordinate system is placed so that the section amidships is in the YZ-plane at the moment $t=0$.

- The origin of a $\xi \eta$ is located at the impact point $C$, the $\xi$-direction is normal to the impact surface and the angle between the $X_{1}$-axis and the $Y_{2}$-axis is $\beta$.

(b)

Figure 1: (a) Geometrical model of the target ships. They are denoted as single skin structure (SSS) and double skin structure (DSS). (b) Simplified coordinate system for ship collision based on analytical theory diagram of ship collision by Zhang [11]. 
Table 3: Mechanical properties of the proposed materials.

\begin{tabular}{cccccc}
\hline Notation & Grade & Density $\left(\mathrm{kg} / \mathrm{m}^{3}\right)$ & $\begin{array}{c}\text { Modulus elasticity } \\
(\mathrm{MPa})\end{array}$ & Yield strength $(\mathrm{MPa})$ & $\begin{array}{c}\text { Ultimate strength } \\
(\mathrm{MPa})\end{array}$ \\
\hline I & A & 7870 & 200000 & 370 & 440 \\
II & B & 7858 & 205000 & 395 & 470 \\
III & D & 7870 & 205000 & 340 & 405 \\
IV & E & 7870 & 205000 & 325 & 385 \\
\hline
\end{tabular}

Table 4: Energy absorption and structural responses after side impact on the side shell.

\begin{tabular}{lcccccccc}
\hline $\begin{array}{l}\text { Structure } \\
\text { types }\end{array}$ & Notation & Grade & $\begin{array}{c}\text { Internal } \\
\text { energy } \\
(\mathrm{MJ})\end{array}$ & $\begin{array}{c}\text { x-stress } \\
(\mathrm{MPa})\end{array}$ & $\begin{array}{c}\text { y-stress } \\
(\mathrm{MPa})\end{array}$ & $\begin{array}{c}\text { z-stress } \\
(\mathrm{MPa})\end{array}$ & $\begin{array}{c}\text { Max shear - } \\
\text { Tresca (MPa) }\end{array}$ & $\begin{array}{c}\text { Critical stress - } \\
\text { von Mises } \\
(\mathrm{MPa})\end{array}$ \\
\hline Single Skin & I & A & 6.545 & 523.3 & 387.6 & 499.3 & 310.5 & 553.2 \\
Structure & II & B & 6.893 & 578.1 & 414.1 & 523.3 & 342.6 & 596.5 \\
(SSS) & III & D & 6.109 & 456.5 & 343.5 & 436.0 & 291.8 & 509.8 \\
& IV & E & 5.860 & 423.0 & 323.2 & 384.4 & 274.4 & 477.4 \\
Double Skin & I & A & 9.083 & 484.6 & 474.3 & 488.9 & 305.7 & 562.5 \\
Structure & II & B & 9.880 & 590.5 & 549.6 & 488.3 & 339.3 & 588.9 \\
(DSS) & III & D & 8.623 & 471.4 & 423.6 & 440.2 & 282.8 & 506.0 \\
& IV & E & 8.294 & 460.1 & 365.2 & 425.8 & 264.7 & 485.9 \\
\hline
\end{tabular}

with proposed strain value in range $0.2-0.35$ would be considered in this work.

\subsection{Scenario preparation}

Two structural types on the struck ship namely the single and double skin structures (SSS and DSS respectively) were determined to be the main targets of the side impact by the striking ship. Condition in collision process was assumed with the collision angle was perpendicular $\left(\beta=90^{\circ}\right)$ when the striking ship approached the target. The rigid-striking ship was given by the constant velocity $V_{c}=10$ knots or approximately equalled with $6.17 \mathrm{~m} / \mathrm{s}$ [30]. The struck ship as the target was set to be fixed on the centreline. The end of the model was clamped with fixation was applied on the transverse frame and longitudinal deck. Boundary conditions were determined to restrain both axial and rotational displacements. Crashworthiness criteria were to be evaluated in forms of the internal energy to assess amount of energy absorption, while stress and damage contours were summarized to estimate failure tendency on different structural types.

\section{Results and discussion}

\subsection{Structural behaviours accounting for structural aspects}

Characteristic of the energy absorption and structural resistance was related each other, which could be assessed in the end of penetration to the struck ship. During the target was determined to be the side shell (Table 4), the double skin structure was evidenced to be better than the single skin style in terms of the energy absorption (presented by the internal energy) during the struck ship was targeted. The biggest difference was recorded on the single and double skin structures applied by the Material II - Grade B with the yield strength $\sigma_{Y}=395 \mathrm{MPa}$. However this tendency did not occurred on the penetration to the main deck. As shown in Table 5 that the difference was lower than value obtained on the collision scenario to the side shell (with approximation 50-75\%). Furthermore, during collision to the main deck, the single skin structure was superior to the double skin structure, but with slight difference in ranges $9-13 \%$. It was also noted that determining the main deck as the target did not produce significant failure on the inner skin which actually the most important part in safety assessment. 
Table 5: Energy absorption and structural responses after side impact on the main deck.

\begin{tabular}{lcccccccc}
\hline $\begin{array}{l}\text { Structure } \\
\text { types }\end{array}$ & Notation & Grade & $\begin{array}{c}\text { Internal } \\
\text { energy } \\
(\mathrm{MJ})\end{array}$ & $\begin{array}{c}\text { x-stress } \\
(\mathrm{MPa})\end{array}$ & $\begin{array}{c}\text { y-stress } \\
(\mathrm{MPa})\end{array}$ & $\begin{array}{c}\text { z-stress } \\
(\mathrm{MPa})\end{array}$ & $\begin{array}{c}\text { Max shear - } \\
\text { Tresca (MPa) }\end{array}$ & $\begin{array}{c}\text { Critical stress - } \\
\text { von Mises } \\
(\mathrm{MPa})\end{array}$ \\
\hline Single Skin & I & A & 10.279 & 546.1 & 384.5 & 225.9 & 307.6 & 536.4 \\
Structure & II & B & 10.984 & 572.9 & 430.7 & 396.2 & 340.6 & 591.9 \\
(SSS) & III & D & 9.406 & 465.0 & 364.8 & 461.0 & 276.1 & 489.9 \\
& IV & E & 9.258 & 482.9 & 343.9 & 446.0 & 272.1 & 471.9 \\
Double Skin & I & A & 9.123 & 574.5 & 476.7 & 529.9 & 313.6 & 544.0 \\
Structure & II & B & 10.161 & 607.2 & 520.9 & 567.0 & 333.4 & 584.8 \\
(DSS) & III & D & 8.592 & 491.7 & 421.1 & 466.2 & 273.4 & 482.5 \\
& IV & E & 8.282 & 466.3 & 431.8 & 496.3 & 244.7 & 480.1 \\
\hline
\end{tabular}

Besides energy absorption, the structural resistance was discussed by assessing the behaviour of occurred stress on the struck ship. Value of the shear stress was represented by Tresca criterion, and critical stress presented by von-Mises criterion, was found equally perpendicular with the absorbed energy, which higher energy would cause larger stress on the structure embedded by stronger material. Observation on the stress value per directions (according to the Cartesian coordinate system) concluded that expansion of structural failure occurred on the $x$-axis or longitudinal direction, and followed by the $\mathrm{z}$-axis or vertical direction for impact to the side shell. This tendency was highly influenced by structural geometry of the side shell which was similar with the stiffened plates (see references [31-33]) with less longitudinal components such as deck strengthened this target. Based on this finding, it also could be estimated that the tearing occurred on the outer skin with T-pattern in moment of the side collision. The initial conclusion for the stress expansion was found to be valid as difference tendency was found on collision case to the main deck. The highest stress still occurred on the longitudinal direction, but not on the second place which now the y-axis or transversal direction was superior to the z-axis or vertical direction. Therefore in this collision scenario, stress spread on main deck with only lower stress level was found on the outer skin. This statement was also to be the main explanation for the early phenomenon that side collision to the main deck provided less effect and damage to the inner skin. Comparative discussion of the side shell and main deck was continued by assessing significance of these target locations to the internal energy during side impact produced penetration to the struck ship.

Structural behaviour of the single side skin against side impact indicated quite remarkable distinction for different target locations. As presented in Figure 2 that the up-

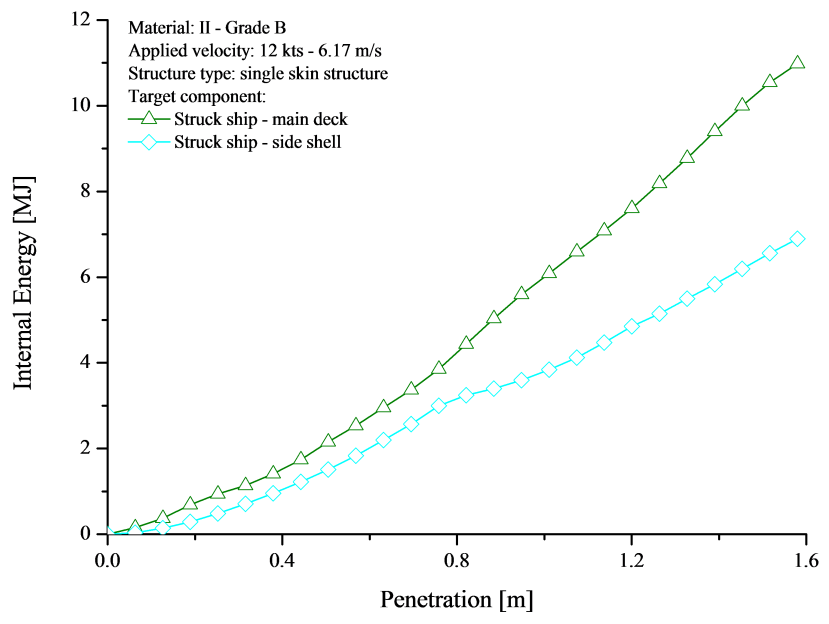

Figure 2: Behaviour of the internal energy vs. bow penetration: single skin structure.

per side structure strengthened by the longitudinal deck exceeded $10 \mathrm{MJ}$ while the side shell was lower than $7 \mathrm{MJ}$ in the end of the striking ship's penetration. Meanwhile, the double skin structure only produced low difference (approximately $3 \%$ ) even though it was targeted on two different locations. Contribution of the inner skin which acted as the final protection of cargo, also hold critical role to strengthen the outer skin in moment of accidental impact. This tendency became might be the most important background of the double skin structure implementation after Oil Pollution Act (OPA) for tankers in early stage, and it was expanded for developed steel constructions of other merchant and passenger ships [34].

Influence of single and double skin structures on the behaviour during collision analysis was also found on the crushing force. Similar to stress, the force was given in Figures 4 and 5 for the single and double skin structures consecutively, by three axes to match the with structural fail- 


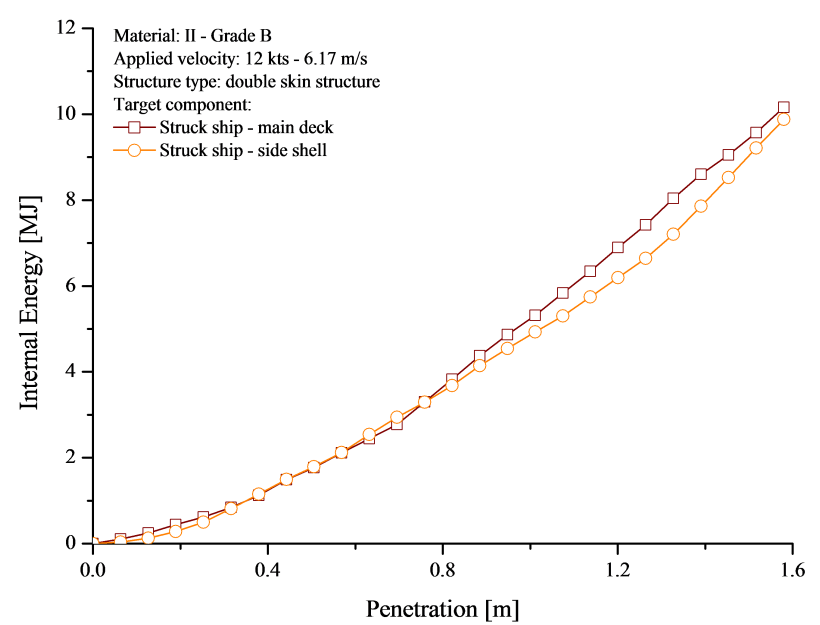

Figure 3: Behaviour of the internal energy vs. bow penetration: double skin structure.

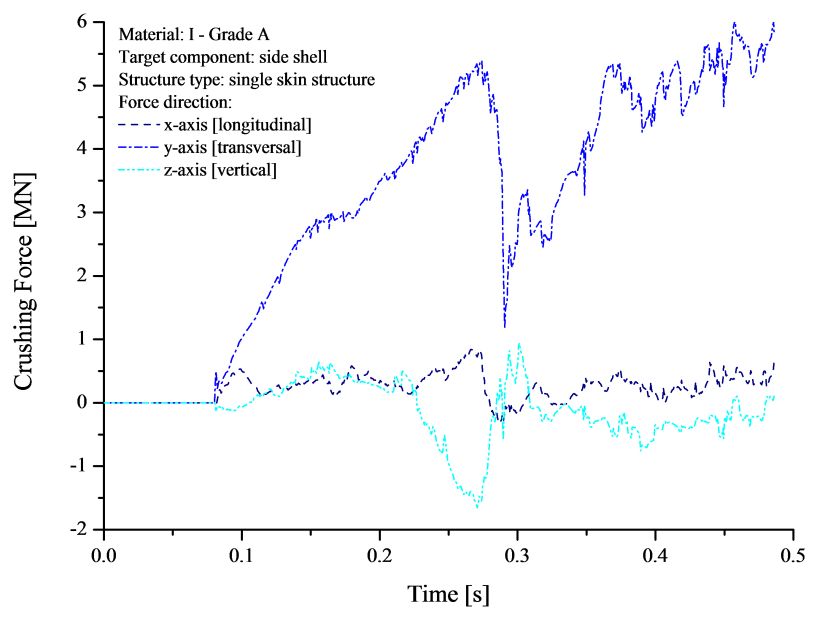

Figure 4: Verification of energy characteristic by the crushing force: single skin structure.

ure in coming discussion. Similarity was achieved for both structures that the most remarkable force occurred on the $y$-axis or in line with coming direction of the striking ship. However, the single skin indicated the y-force only fluctuated in positive direction, while the double skin produced higher force to negative direction. These results were obtained since in the single skin, crushing process only took place on the outer skin which no inner skin was located in this structural types. Structure crush could be estimated stopped after the outer skin was successfully penetrated in the side impact (see Figure 6 on the upper side). Meanwhile, the inner skin of the double skin structure experienced failure in terms of tearing (see Figure 6 on the lower side) which indicated that the crushing process was continuously experienced by the struck ship after the outer skin was breached by the striking ship. Confirmation of

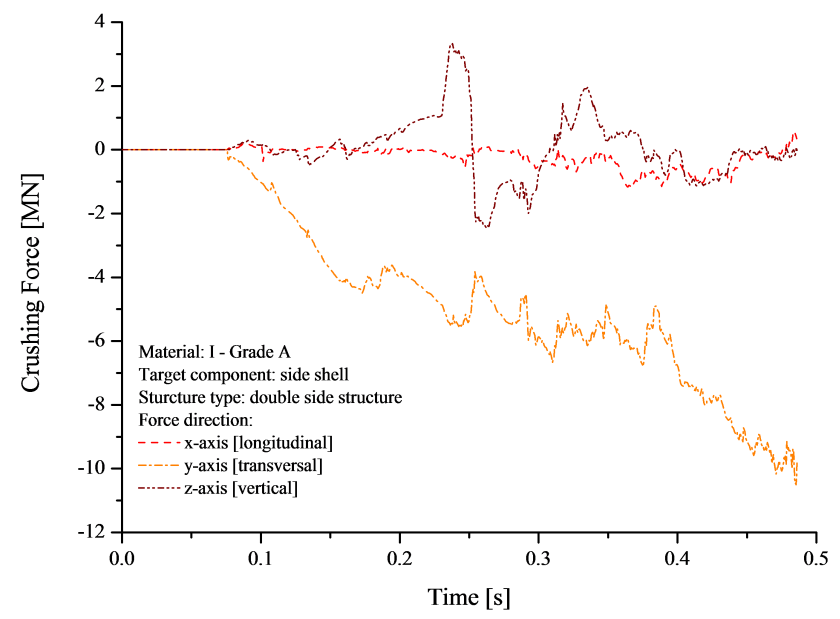

Figure 5: Verification of energy characteristic by the crushing force: double skin structure.

crushing process on both structures was shown by failure strain contours in Figure 6 which strain only expanded on the outer skin for the single skin structure or SSS, and the tearing damage of the inner skin was surrounded by the strain for the double skin structure or DSS.

\subsection{Contribution of steel material}

Effect of the proposed materials to structural behaviours can be assessed based on the failure and energy. Failure would be proportional with the damage volume, while the internal energy represented the energy absorption. These crashworthiness criteria were previously described as related factors in empirical approaches [10, 13, 21-23]. Presented results in Figure 7 indicated that difference on tearing was more visible by observing failure extent on the DSS since another structure produced similar damages in length and width. It was obtained that material with higher yield strength was capable to concentrate the failure on outer skin, and reduced failure size on the inner skin, especially the failure length. The material II - Grade $\mathrm{B}$ as the strongest material produced the smallest tearing length on the inner skin and largest failure on the outer skin among of all proposed materials. However, tearing width on the inner skin was very small with remarkable difference was not found. It achieved good correlation with illustration in Figure 6 for DSS that remarkable failure contours expanded on the outer skin but only small failure strain contour was found near the tearing on the inner skin.

Behaviour of the occurred energy during collision analysis also should be given adequate attention to evalu- 

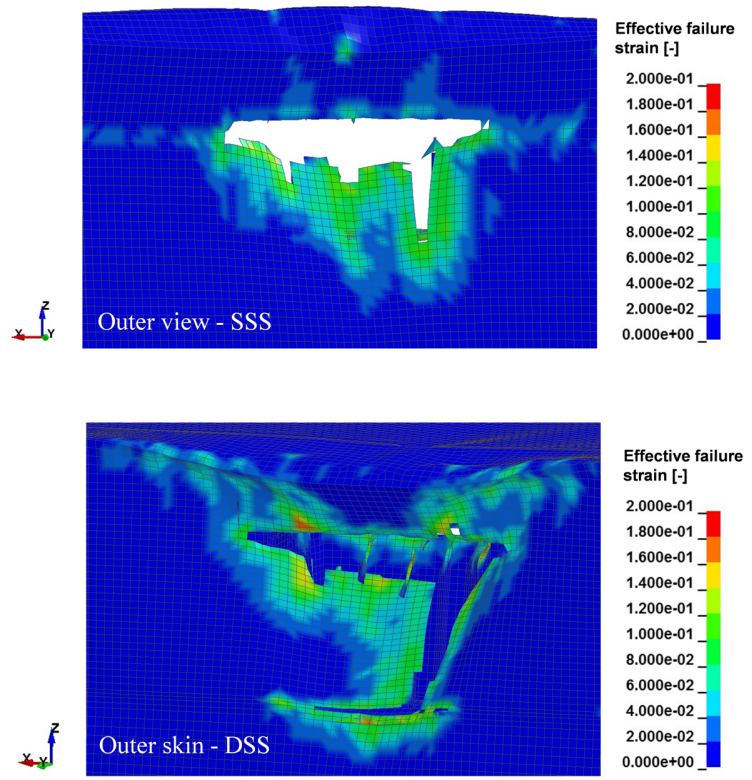

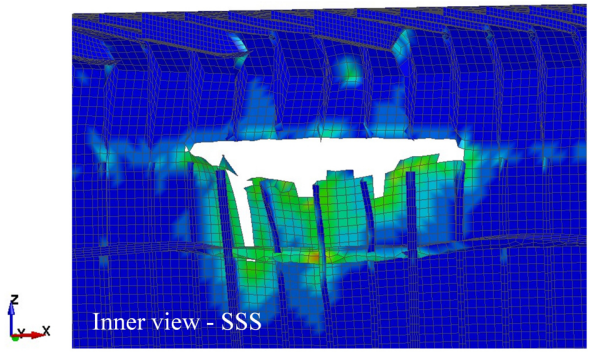

Effective failure strain [-]

2.000e-01 $1.800 \mathrm{e}-01$ $1.600 \mathrm{e}-01$ $1.400 \mathrm{e}-01$ 1.200e-01 $1.000 \mathrm{e}-01$ $8.0000-02$ 6.00002 $6.000 \mathrm{e}-02$ $4.000 \mathrm{e}-02$ $2.000 \mathrm{e}-02$ $0.000 \mathrm{e}+00$

Figure 6: Structural failure on the single and double skin structures: penetration to the side shell with the applied material I - Grade A with $\sigma_{Y}=370 \mathrm{MPa}$.

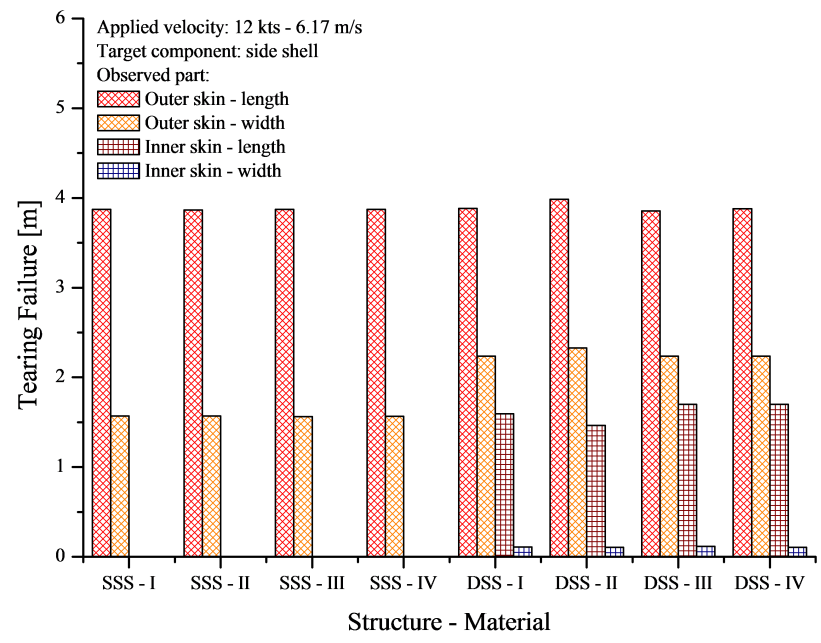

Figure 7: Failure on the struck ship accounting for determined structures and materials.

ate structural response. Internal energy was found equally perpendicular with the recorded total energy in Figure 8. Since same value for the applied velocity was used, the kinetic energy was same for all scenarios. However, the occurrence of the hourglass energy was to be a recommendation for further work in impact to complex structures. Hourglass was described as condition of the structure to experience anomaly or natural shape due to excessive strain and remarkable damage. Larger the energy might lower validity of the analysis results. Even though the hourglass was very low in present work, application of

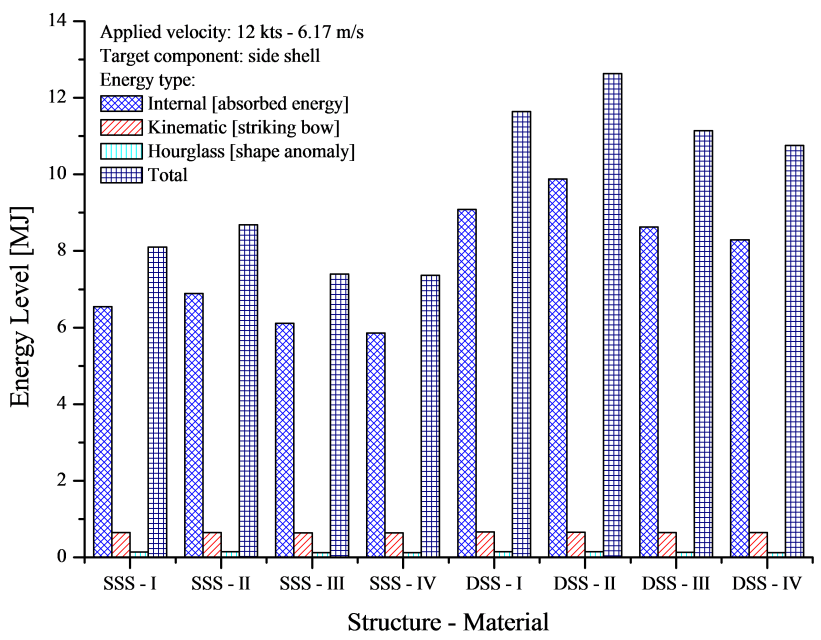

Figure 8: Energy behaviour in virtual experiment for all designed collision scenarios.

fully integrated Belytschko-Tsay shell formulation EF no. $=12$ was judge well enough to avoid hourglass in collision and grounding analysis by nonlinear FE method $[35,36]$.

Final verification of the presented results in Figure 7 for tearing sizes on the inner skin was shown by comparing the failure strain after side impact. Even though it was not significant, results in Figure 9 gave an indication that contour expansion for the material II - Grade B was the narrowest which concentrated near the tearing. Meanwhile, two weaker materials, such as the material III - Grade D and material IV - Grade E, experienced slight 

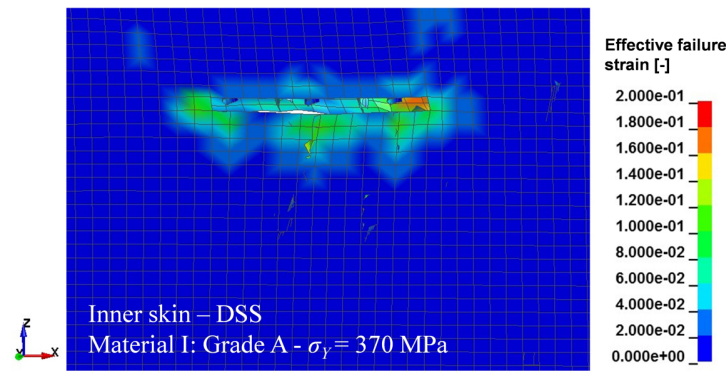

$0.0000+00$

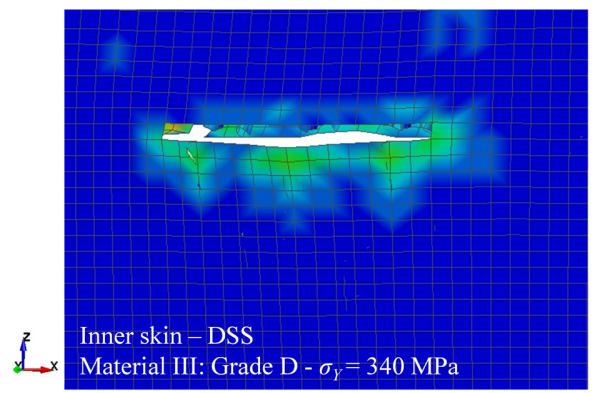

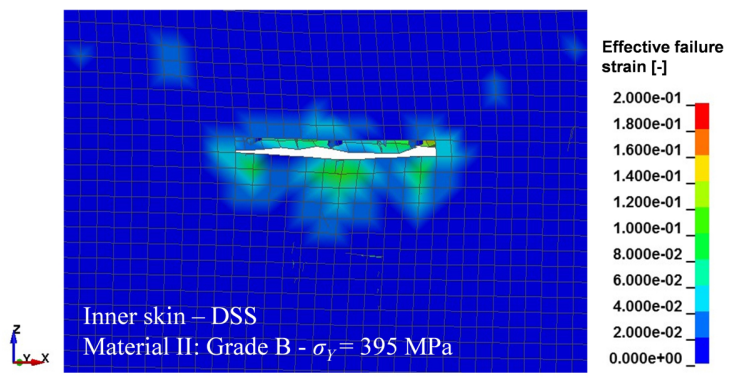

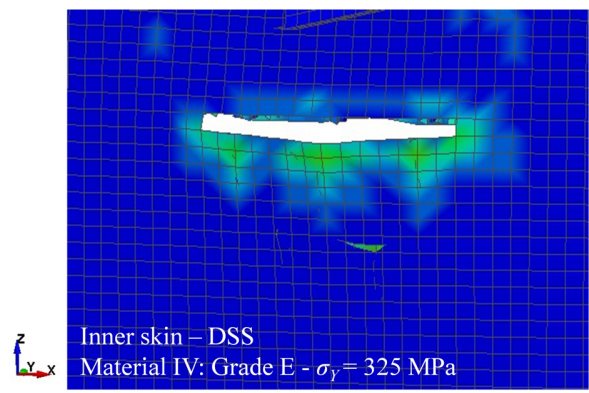

Effective failure

strain [-]

2.000e-01

$1.800 \mathrm{e}-01$

$1.600 \mathrm{e}-01$

$1.400 \mathrm{e}-01$

1.200e- 01

1.000e-01

$8.000 \mathrm{e}-02$

$6.000 \mathrm{e}-02$

$4.000 \mathrm{e}-02$

$2.000 \mathrm{e}-02$

$0.000 \mathrm{e}+00 \_$

Figure 9: Conditions of the inner skin after later impact. Contour expansion indicated that less failure strain and tearing length were experienced by the Material II - Grade B with $\sigma_{Y}=395 \mathrm{MPa}$.

larger contour on the right side of tearing failure than the material I and II. It indicated that the material with minimum value of the yield strength $\sigma_{Y}=370 \mathrm{MPa}$ had better capability in resisting side collision. Specifically, this result was achieved when the striking ship with relative size was approximately $40 \%$ larger in length than the struck ship. Larger size of the striking ship can deliver wider tearing and failure contour on the inner shell, which is considered dangerous for cargo and ship structure. Observations of material capability and structural resistance using the current setting are encouraged to be extended using rebounding assumption [19] in further works.

\section{Conclusions}

This paper was addressed to analyse structural behaviour against impact load given by side collision with other ship. Focus was given to internal mechanics of ship collision, which structural type and material strength were considered as the observed parameters. Behaviour of the energy absorption represented by the internal energy indicated that the double skin structure was successfully improve structural performance of the conventional single skin hull. Results were more conveniently observed by evaluate the impact scenario to the side shell than the main deck. The second target was found provided less failure to the outer and inner skins, and concentrate the crushing pro- cess on the deck. Further study to quantify effect of structural target, such as longitudinal deck, to rebounding of the striking ship could be an attractive research plan. Disparity of the side shell and main deck was found very low on the DSS while remarkable distinction was concluded on the SSS, which indicated contribution of the inner skin was successfully structural resistance in case of accidental side collision to the ship hull. Proposed materials together with ship structure acted as a protection against the side collision were discussed in this study. Material with higher yield strength was more capable in resisting penetration. Application of variance in velocity types (i.e. constant and initial values), and different shell formulations in respect time simulation and disadvantageous phenomena, such as hourglass and shear locking is recommended to be considered.

\section{References}

[1] Allianz, Safety and Shipping 1912-2012, From Titanic to Costa Concordia. Allianz Global Corporate \& Specialty, Munich, Germany, 2012.

[2] T.L. Yip, W.K. Talley, D. Jin, The effectiveness of double hulls in reducing vessel-accident oil spillage. Mar. Poll. Bul. 62 (2011) 2427-2432.

[3] Y. Zheng, S. Aksu, D. Vassalos, C. Tuzcu, Study on side structure resistance to ship-ship collisions. Ships and Offshore Struct. 2 (2007) 273-293. 
[4] H.W. Leheta, S.F. Badran, A.S. Elhanafi, Ship structural integrity using new stiffened plates. Thin-Walled Struct. 94 (2015) 545561.

[5] D.K. Park, D.K. Kim, J.K. Seo, B.J. Kim, Y.C. Ha, J.K. Paik, Operability of non-ice class aged ships in the Arctic Ocean-part II: Accidental limit state approach. Ocean Eng. 102 (2015) 206-215.

[6] B. Sun, Z. Hu, G. Wang, An analytical method for predicting the ship side structure response in raked bow collisions. Mar. Struct 41 (2015) 288-311.

[7] D.M. Bae, A.R. Prabowo, B. Cao, J.M. Sohn, A.F. Zakki, Q. Wang, Numerical simulation for the collision between side structure and level ice in event of side impact scenario. Lat. Am. J. Sol. Struct. 13 (2016) 2991-3004.

[8] A.R. Prabowo, J.M. Sohn, D.M. Bae, J.H. Cho, Performance assessment on a variety of double side structure during collision interaction with other ship. Curved and Layer. Struct. 4 (2017) 255-271.

[9] A.R. Prabowo, T. Muttaqie, J.M. Sohn, D.M. Bae, A. Setiyawan, On the failure behaviour to striking bow penetration of impacted marine-steel structures. Curved and Layer. Struct. 5 (2018) 68 . 79.

[10] V.U. Minorsky, An analysis of ship collision with reference to protection of nuclear power ships. J. Ship Res. 3 (1958) 1-4.

[11] D. Chen, Simplified Ship Collision Model. Virginia Polytechnic Institute and State University, Virginia, US, 2000.

[12] M. Lützen, Ship Collision Damage. Technical University of Denmark, Lyngby, Denmark, 2001.

[13] S. Zhang, The Mechanics of Ship Collisions. Technical University of Denmark, Lyngby, Denmark, 1999.

[14] J.K. Paik, Practical techniques for finite element modelling to simulate structural crashworthiness in ship collisions and grounding (Part I: Theory). Ships and Offshore Struct. 2 (2007) 69-80.

[15] J.K. Paik, Practical techniques for finite element modelling to simulate structural crashworthiness in ship collisions and grounding (Part II: Verification). Ships and Offshore Struct. 2 (2007) 81-85.

[16] O. Kitamura, FEM approach to the simulation of collision and grounding damage. Mar. Struct. 15 (2002) 403-428.

[17] S. Haris, J. Amdahl, Analysis of ship-ship collision damage accounting for bow and side deformation interaction. Mar. Struct. 32 (2013) $18-48$

[18] B. Liu, C.G. Soares, Assessment of the strength of double hull tanker side structures in minor ship collisions. Eng. Struct. 120 (2016) 1-12.

[19] A.R. Prabowo, D.M. Bae, J.M. Sohn, A.F. Zakki, B. Cao, J.H. Cho, Effects of the rebounding of a striking ship on structural crashworthiness during ship-ship collision. Thin-Walled Struct. 115 (2017) 225-239.

[20] R. Szłapczyński, R. Śmierzchalski, Supporting navigator’s decisions by visualizing ship collision risk. Polish Mar. Res. 16 (2009) 83-88.
[21] G. Woisin, Design against collision. Schiff \& Hafen 31 (1979) 1059-1069.

[22] G. Lu, C.R. Callidine, On the cutting of plate by a wedge. Int. J. Mech. Sci. 32 (1990) 293-313.

[23] J.K. Paik, Cutting of a longitudinally stiffened plate by a wedge. J. Ship Res. 38 (1994) 340-348.

[24] O. Ozguc, P.K. Das, N. Barltrop. A comparative study on the structural integrity of single and double side skin bulk carriers under collision damage. Mar. Struct. 18 (2005) 511-547.

[25] A.R. Prabowo, D.M. Bae, J.M. Sohn, A.F. Zakki, B. Cao, Q. Wang, Analysis of structural behavior during collision event accounting for bow and side structure interaction. Theo. App. Mech. Let. 7 (2017) 6-12.

[26] IACS. Requirements Concerning Materials and Welding. International Association of Classification Society, London, UK, 2016.

[27] ANSYS. ANSYS LS-DYNA User's Guide. ANSYS Inc., Pennsylvania, US, 2017.

[28] D.M. Bae, A.R. Prabowo, B. Cao, A.F. Zakki, G.D. Haryadi, Study on collision between two ships using selected parameters in collision simulation. J. Mar Sci. App. 15 (2016) 63-72.

[29] R. Törnqvist, Design of Crashworthy Ship Structures. Technical University of Denmark, Lyngby, Denmark, 2003.

[30] A.R. Prabowo, D.M. Bae, J.H. Cho, J.M. Sohn, Analysis of structural crashworthiness and estimating safety limit accounting for ship collisions on strait territory. Lat. Am. J. Sol. Struct. 14 (2017) 1594-1613.

[31] J.K. Paik, J.K. Seo, A method for progressive structural crashworthiness analysis under collisions and grounding. Thin-Walled Struct. 45 (2007) 15-23.

[32] H.S. Alsos, J. Amdahl, On the resistance to penetration of stiffened plates, Part I - Experiments. Int. J. Impact Eng. 36 (2009) 799-807.

[33] R.E. Oshiro, M.A.G. Calle, L.M. Mazzariol, M. Alves, Experimental study of collision in scaled naval structures. Int. J. Impact Eng. 110 (2017) 149-161.

[34] D.J. Eyres, Ship Construction. Butterworth-Heinemann, Oxford, UK, 2001.

[35] A.R. Prabowo, H.J. Cho, J.H. Byeon, D.M. Bae, J.M. Sohn, Investigation of impact phenomena on the marine structures: Part I - On the behaviour of thin-walled double bottom tanker during rock-structure interaction. J. Phys.: Conf. Series 953 (2017) 012003.

[36] A.R. Prabowo, S.J. Baek, S.G. Lee, D.M. Bae, J.M. Sohn, Investigation of impact phenomena on the marine structures: Part II - Internal energy of the steel structure applied by selected materials in the ship-ship collision incidents. J. Phys.: Conf. Series 953 (2017) 012002. 